\title{
The Importance of Engineer Image in Society: Understanding Engineer's Representation in the Mind of Tunisian Entrepreneurs
}

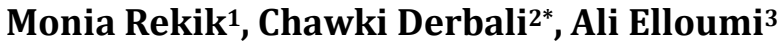 \\ ${ }^{1}$ University of El-Manar, Tunis, Tunisia \\ ${ }^{2}$ Research Unit, Sports Performance and Physical Rehabilitation, University of Jendouba, Kef, Tunisia \\ ${ }^{3}$ Laboratory TEC, University of Paris Descartes, Paris, France \\ Email: moniesocio@yahoo.com, *derbali_chawki@yahoo.fr, alielloumi62@gmail.com
}

How to cite this paper: Rekik, M., Derbali, C., \& Elloumi, A. (2018). The Importance of Engineer Image in Society: Understanding Engineer's Representation in the Mind of Tunisian Entrepreneurs. Advances in Applied Sociology, 8, 534-561.

https://doi.org/10.4236/aasoci.2018.87032

Received: June 25, 2018

Accepted: July 22, 2018

Published: July 25, 2018

Copyright $\odot 2018$ by authors and Scientific Research Publishing Inc. This work is licensed under the Creative Commons Attribution-NonCommercial International License (CC BY-NC 4.0).

http://creativecommons.org/licenses/by-nc/4.0/

\begin{abstract}
This paper aims to investigate a new perspective that can incrementally analyze framework of entrepreneurs' representations with regards to engineer image. It identifies managers' attitudes towards the engineer and reveals the real factors that can explain the policy of hiring senior technicians in the Tunisian Cap-Bon industry. The sociological analysis of the representation of the industrial company leader on the issue of executive recruitment engineers had helped to highlight the risks of driving performed changes, the discrepancy between managerial objectives and how implement decisions. The ultimate consequences of this inconsistency can brake recruiting new engineers. Results highlight the influence of the entrepreneurs' representations on the employment issue. Analysis of attitudes demonstrates that mind of leader towards framework engineer seems irrational, as long as, leader integrates technical uncertainties related to organizational and economic changes. In line with the main study, these social representations of the frame could be made on configurations, opinions, habits, equity positions, varied and often contradictory. If we are willing to embrace the idea that there would be a "change" in entrepreneurs' representations towards engineers, it might be incrementally achieved through a triple register: cognitive, strategic and ethical.
\end{abstract}

\section{Keywords}

Social Representation, Recruitment Strategy, Managerial Ethics, Engineer, Change

\section{Introduction}

The study of social representations has developed considerably by Moscovici 
(1961) and comparatively overviewed by Jodelet (1989). The notion of representation occupies a special place in social psychology. It was introduced by Durkheim as the notion of collective representations and assigned in his social psychology study. Moscovici (1961) analyzes the way in which a "scholarly" discourse is transformed into a "common sense" discourse. That is, the way we go from a system of theoretical concepts to a system of representations. The author highlights how media present information and construct particular representations of psychoanalysis in their readers. It seeks here to define which image is conveyed. Then, Moscovici, survey of individual readers to know the image they have of psychoanalysis and this by means of interviews. For social representation to be functional, two mechanisms must be put in place: Objectivation consists in reducing, transforming what is conceptual into concrete, and assigning a function to it like considering psychoanalysis as an object. Then, the anchoring phase of social representation consists in linking this object to other representations with contrast, assimilation link or comparative. In short, mental representations are actualized through linguistic indicators of expressions that translate a relation of the individual to reality. For example, Jodelet (1985) conducted a study in a rural area where mentally ill people were free at home. She was able to show that the representation of mental illness was actualized through particular expressions.

Beside this issue and the overview theory, we can inquire about representations in the professional and economic life. For the key question in relation with the present study we search: how understanding the engineer image in Tunisian society? The encountered issue with the notion of society entrepreneurial success is that it has been largely studied by researchers who tried to map the factors leading to it without taking position on what it was and what it must be (Resmi \& Kamalanabhan, 2010).

At this age of globalization in all its forms (competition, goods and service markets, technologies, concentration, displacement of corporations, capital open markets), companies have to adapt to the new strategic schemes; they have needs for new skills and, therefore, they must face the challenge in terms of hiring, promoting and rewarding their employees. In this new setting, and in wider, economic, ethical, cultural and social dimensions, competition has become the engine of all kinds of evolutions. It directly and indirectly affects corporations, and influences training institutions so deeply, thus affecting training candidates as well.

For this reason, enterprises are faced with the need to hire engineers who have been trained in Tunisian universities. They have to choose the best engineers in advanced fields, as an innovation source, while maintaining their competitiveness. The selection criteria evolve necessarily from permanent wakefulness. Without reaching the well-defined, long-term strategies, entrepreneurs and corporation managers in the Cap-Bon (located in the extreme north-east of Tunisia) are required to shed light on the new situation created by globalization, and especially, to appreciate the main factors that may lead them to adapt their 
uses of those engineers who have graduated from Tunisian higher education and training institutions. They are also required to inform those institutions of new specifications. Among those factors, our present study will particularly focus on the location strategies of decision centers, as well as those of development and production that affect companies' hiring and employment policies.

Because of the evolution of various social company models, the XXI century obliges us to think about a new social company model that would allow articulating the capacities of economic reactions to the multiple contingencies of the market. During the years 1980 and 1990, the Tunisian government was first confined to negotiating structural adjustment plans with financial institutions. Then, its withdrawal from the production field paradoxically led to the poor guidance of the productive sector, though in Tunisia, the education system continues to train engineers in large numbers. In fact, the number of graduate engineers increased five-fold between 2002 and 2014, reaching 7275 graduates. This evolution can't be explained merely by the pressure of baccalaureate students, whose total number was steady (around 74.000) during that period. The rise has been particularly fast for the last five years, with a noticeable increase in training offers at the private engineering schools and universities, whose size has evolved from $26 \%$ to $41 \%$ in terms of $3^{\text {rd }}$ year students between 2009 and 2014 . It is estimated that 6.200 engineers per year will be required for training in 2020 and 7.000 in 2025 (OIT, 2015).

Various training types are affected by the national engineering diploma.

A double selection path: preparatory classes and national selective exam, exclusively public, attracting $42 \%$ of the total mass.

A path via the baccalaureate exam, attracting $56 \%$ of the total mass, with an integrated preparatory phase or a closed competition for the license holders (GEFI, 2015).

Moreover, some authors have highlighted the existing contradiction between the weakness of an endogenous technological development and phenomena such as the marginalization of engineers in the production process, especially at the level of technological choices (Ben Salem, 1994). This explains the unemployment rate of engineers in Tunisia: 10\% 1.500 (2005); 16\% 6.000 (2013); 25\% $\sim 10.000$ (2014) in (Young graduates of higher education and employment in Tunisia, 2010).

The economic liberalization raises the crucial problem of the position of developing countries in the international work division. In the case of Tunisia, the poor quality of specialization in the field of widespread technologies explains the reason why, in the chief industrial economic sectors (textile, leather, electronics and mechanics), the number of engineers is low. As a result, the Tunisian development models tend to make the lowering of the employment cost the only criterion of competitiveness.

Moreover, enterprises would rather not hire highly-qualified staff, even if this is often done at the expense of maximizing the added value (This value makes it possible to measure the exact contribution of a production unit to the creation of 
wealth). In fact, we will particularly focus in our study on the level of guidance in industrial enterprises according to the corporation manager, which affects the employment of senior technicians.

Asked about the category of engineer, enterprise managers defend attitudes that are both in favour and against the issue. Those people have strong views on it. How is this ambiguous attitude reflected on the industrial enterprise? Knowing that managers' attitudes have an impact on the success of the employment policy in Tunisia, and, especially, at the level of hiring senior engineers, we may wonder about the reasons for their attitudes and their representations of the engineer.

Next to (Ben Salem, 1994) only very small number almost negligible of engineering employable, which doesn't exceed $1 \%$ of the total number of employees in the Cap-Bon industry: what's wrong with Tunisian engineers? This leads us to ask about the real causes of this poor guidance in the industrial enterprises of the area. However, it is worth wondering why those enterprises haven't hired a high number of engineers that match with their expansion in spite of the industrial development in the region. Is that for financial reasons in order to reduce the production cost? Or for others cultural, organizational or psycho sociological reasons?

For these reasons, we will try to identify managers' attitudes towards the engineer and reveal the real factors that can explain the policy of hiring senior technicians in the Cap-Bon industry. For this purpose, each point in this analysis will be linked to the engineer in order to enrich the issue. An empirical study will answer our enquiry. It aims at obtaining three-aspect data.

\section{Methods and Tools}

\subsection{Purpose}

We will try to identify managers' attitudes towards the engineer and reveal the real factors that can explain the policy of hiring senior technicians in the Cap-Bon industry. For this purpose, each point in this analysis will be linked to the engineer in order to enrich the issue. An empirical study will answer our enquiry. It aims at obtaining three-aspect data.

\subsection{Experimental Protocol}

\section{Questionnaire Process}

Throughout this work, the empirical research was done by means of a questionnaire targeted at selected within the specified Tunisian Cap Bon. The questionnaire contains the relevant questions to support the research. The questionnaires focus on giving meaningful information regarding the image of Tunisia engineer. Welman, Kruger and Mitchell (2007) explain that quantitative research methods may be observed objectively and that it exists independently of opinions and feelings of community.

This study is based on the questionnaire measuring entrepreneurs' orienta- 
tions in business developed by Miller (1983) and extended by Covin and Weales (2012). It is also grounded on the questionnaire of Lotz and Van Der Merwe (2013) designed to measure the employee's point of view in industrial company and it proved to be successful. The present study questionnaire measures entrepreneurs' representations in regards with Tunisian engineer in Cop Bon. The questionnaire deals with three dimensions of entrepreneurs' representations that have relation with the strategy of employment and success of industrial business. Questionnaire target were the identity of enterprise, the expected behaviour of engineer and the strategy of recreating engineers. In details, we would like to gather facts concerning the type of enterprise responding to the questionnaire (contact details, head of human resources department, activity sector, enterprise status, number of workers), as well as the enterprise behaviour enterprise behaviour in terms of senior engineers' employment (whether they are engaged engineers, the enterprise is ready to hire engineers, the number of hired engineers, enterprise managers' attitude to young engineers: their training, their productivity, the employment procedures, the privileged profiles, the sought skills, the promotion criteria, the means of motivating and integrating new engineers.)

In addition, we would like to collect information about the entrepreneur's subjective judgments of engineers and of the job, (the expectations of the enterprise from an engineers, the definition and representation of a senior engineer, issues to be considered regarding engineers' employment, their integration in the enterprise, the adaptation of the work position, opinions about the reason for the low employment level of engineers in the enterprise....). Finally, we wish to obtain data related to managers' cognitions, more precisely, to their knowledge about engineers' employment. (The flexibility level of the industrial company and its ability to adapt to technical and organizational changes and to the local as well the global environment...).

\subsection{Interviewing Process}

Through this research, we also opted interviewing the heads of enterprises during the period (2014-2015). This allowed us to obtain rich information and reflection hints based on 30 sample bosses. We raised guidance notions in the Industrial enterprises, the engineer's work, as well the key words that the employer could associate with those terms. We also asked the employer to justify some of the questionnaire answer: (How can you justify the number of engineers and that of technicians in terms of sectors and areas? Why is electrical engineering the most employing sectors of engineers $46 \%$ in your own opinion? How can you explain this difference in qualification rates in the different areas (42\% Kelibia, $8 \%$ Korba, $19 \%$ Nabeul, 15\% Soliman)? How can you justify the employment procedures in the different sectors? Textile, metallurgical industry and others via a contest; electro-mechanics and farming via a training course and ceramics and farming via the employment centre? Concerning the selection critera, why is the degree required in textile and other fields, while in ceramics the 
personal profile and team-work tendency are needed, and in agro-food stuffs it is polyvalence that is required?

The intend of this interview is not to obtain an answer to each question, but to use those questions in order to confirm some representations already mentioned in the answers, and find out others. This method is grounded on (Rubin, H. J. \& Rubin, I. S., 2005; Patton, 2001; Kvale, 1996). These qualitative studies of interviewing heads of companies provides a method for collecting wealthy and detailed information about their professional perceptions, understand and explain strategy of recreating engineers in their companies and enquired knowledge about engineer image. Interviews provide greater detail and depth complementary to the quantitative questionnaire, allowing insight into how entrepreneurs understand the place of the engineer and perceived aspects of their image. Additionally, these interviews can be tailored specifically to the knowledge of the entrepreneurs, their experiences and representation face to the engineers in Tunisia. Beside, detailed notes are crucial for transparency of the research all information from the interviewee was registered. We had taking notes on body language, tone of voice, or any other clues as to the meaning of the interviewee. This can give important insight into the meaning of the interviewee (Turner, 2010). After the interview we have transcript all integrates notes that should be produced.

Finally, we examined the employer's experience in terms of engineers' hiring, his way of reacting to certain concrete situations. (For instance, why are maintenance and control engineers needed? Why is partnership with universities required only in the textile, farming and electro-mechanical sectors?) The aim of this interview is not to obtain an answer to each question, but to use those questions in order to confirm some representations already mentioned in the answers, and find out others.

Finally, we equally used the focus-group, reuniting six heads of human resources department as well as private and public enterprise managers. Based on the outcome of the questionnaires and the interviews, we aimed to make employers react in order to better understand the representations resulting from those results, notably the unwillingness of decision-makers in the Cap Bon industry to employ senior engineers, which is related to the everyday happenings and the strategic choices made by those managers. Above all, this is related to their managerial concerns, the procedures and criteria of selecting candidates, the means of professional promotion and advancement, as well as the methods of integration of those senior engineers in the professional life.

\section{Results and Discussions}

\subsection{The Influence of Industrial Managers' Professional Training on Their Representation of Senior Engineers}

The social representations are areas of knowledge that play a role in the maintenance of social bonds. While they are moulded, they transmit some kind of knowledge about those bonds. This intertwining between the representations 
and the social bonds is often ignored. It is a way to interpret and think about out daily reality (Jodelet, 1984). It is made up of all kinds of experiences and information received and transmitted by traditions, education and social communication. It is, therefore, some kind of socially-elaborated and shared knowledge that contributes to the social construction of our reality. We notice that any representation is defined by a content related to an object. It is a representation of something and somebody, an individual, a family, a group, a class, etc...

The dialectic relation between the representation and the social side can be explained through two processes: The objectivation as an imaging and structuring operation of an abstract notion ("figurative core") and the anchor as a social rooting in the life of groups. Having become some kind of common code, the social representation helps to rank individuals, events and objects, and to elaborate prototypes allowing the evaluation of other objects. The prototype, which is never neutral, orientates the ranking by offering a matrix of traits according to which new objects lliw be categorized.

The multiple interpretations of senior technicians in general or of senior engineers in particular conducted by the various institutions of society (university, media, government) lead to a varied and, therefore, complex reading of this object. The managers, who are the actors of the hiring policy, design and image of the engineer in this environment through the production of some kind of knowledge that they receive or search for and that is accessible to them, by constructing representations as an organization of socially-shaped opinions related to a given object, resulting from a set of social communications, allowing them to master the environment and making it appropriate in terms of symbolic elements that are part of the group(s) to which they belong (Bonardi \& Roussiau, 2001).

The representation of the engineer helps understand which positions managers take in relation to this issue. The social representations are useful for studies since they contribute to the training processes as well as those that orientate social conducts and communications (Moscovici, 1961).

Their influence is, therefore, greater than that of "scientific theories". Thus, we can see the importance that representations can take in the decision process, and particularly in deciding whether to hire a new senior technician. The representations that the employer has about that person could influence his choice, directly or indirectly through the attitudes or the expectations that will, in their turn, influence the behaviour of the manager or at least the way he perceives that behaviour (through an expectation-confirming process).

Thus, if we wish to try to find out procedures aiming at promoting the employment of engineers, we need to discover the kind of representations the employers have about the engineer and his role in the efficiency of the enterprise, then find the best ways of modifying those representations.

In our research, we suggest studying the influence of professional training for industrial managers on their representation of the senior manager. Even if each 
industrial boss has his own representation of engineers, linked to his personal history, to the already employed people and to the socio-economic context in which he works, it is difficult not to envisage managers in the Cap Bon industrial sector as a social group making an entity, sharing a certain representation of senior engineers and possessing a common professional identity. This reflects their social belonging. Sharing an idea or a language is also affirming a social link and an identity (Jodelet, 1984).

Social representations govern individual behaviours and their attributions. Those representations aren't universal, but they are shared by all the members of the same social group, they have a social-differentiation function. The process underlying those representations is nothing but that of social grouping through which group relations are elaborated, which means that the attributions depend on the representations of individuals and their sectorial belonging according to Doise (1973).

It is important to distinguish an "attribution theory" that focuses on attribution antecedents, described in terms of information, as beliefs and motivations, as an "attributive theory" that deals with the consequences of attributions, that is the manipulation or distribution of the perceived causes and of the extent of their effects on the behavious, feelings and expectations according to Kelly and Michela (1980). The attribution process is a psychological process that tends to rank the environment in terms of categories: groups of people, objects, events, some of their attributes, as long as they are either similar or equivalent to each other in action, intentions or individual attitudes (Tajfel, 1972).

The values related to the social category are manifested through different levels: at the level of judgement, attitude or social groups; the individuals use the information that they think is correlated. For example, a personality description allows behaviour grouping. At the opinion and attitude evaluation level, values play the same role as the grouping process, when it interferes with judgments and opinions. Attitudes are regulated according to the values to which those who must make the judgments adhere. When we plan to study attitudes in a global society, it is important to detect the particularities of the social elements that generate those representations. Differentiating with precision the social groups will contribute to the analysis of the common points between the members of the samples involved in our research.

That's why; we will design detailed demographic questions in order to have an exhaustive outlook of the characteristics of the studied population.

\subsection{The Status of Senior Engineers in the Cap-Bon Industry}

The mother population represents 1754 industrial enterprises in the Cap Bon in 2014 (The Cap Bon Chamber of Commerce and Industry). The population of the chosen sample represents 1132 enterprises in the industrial fields requiring engineers' explorations. Then, the sample of the empirical research is chosen among the 267 enterprises divided according to the following criteria: the num- 
ber of employees (over fifty employees), and the importance of their turnover. That is, we focused in our choice on the enterprises that enjoy good economic benefit in the Cap Bon area, so this sample represents 124 enterprises that is $60 \%$ of the total number of enterprises that exploit engineers' skills.

If we take the kind of engineers (Figure 1), we notice that more than $2 / 3$ of them work in Grombalia, Soliman and Nabeul. This concentration is to be linked to the predominant sectors in those three areas, namely electronic mechanics (Grombalia), agri-food stuffs industry (Soliman and ceramics (Nabeul). It is worth mentioning that those three areas together involve a great proportion of industrial enterprises.

We also notice that $1 / 5,21 \%$ of all the engineers, are found in Beni-Khalled and Bouargoub (11\% - 10\%). As for technicians, more than a third of them work in Nabeul 36\%, a fifth in Soliman and a little less than a fifth, 17\% in Grombalia. The relatively high proportions of technicians can be explained by the great concentration. In fact, the technical training rate is relatively high in the developed

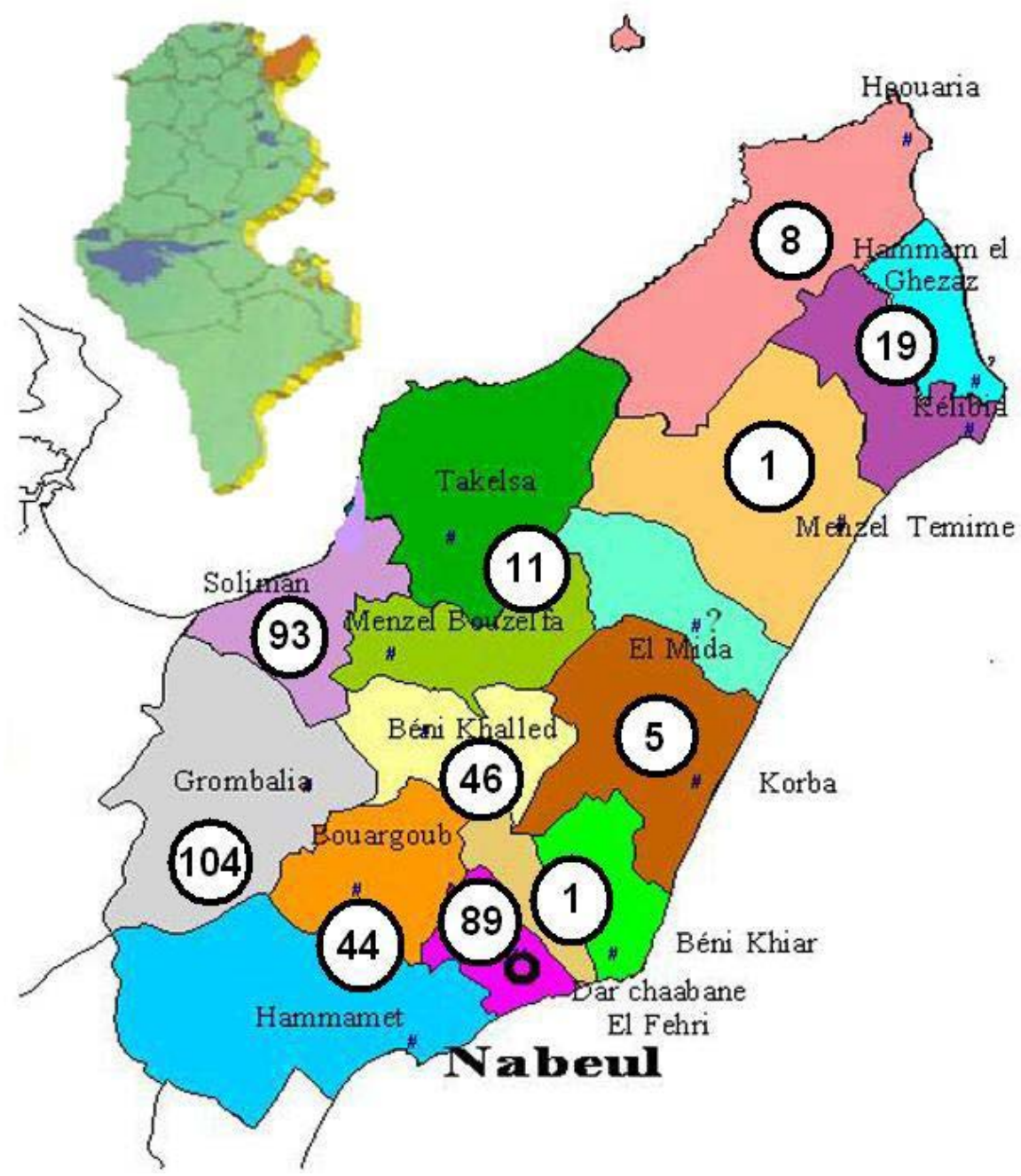

Figure 1. Distribution of engineers' number indicating 11 selected cities for investigation in the Cap Bon industry area of Tunisia (Cap Bon, located in the extreme north-east of Tunisia, surrounded by the Mediterranean on sides of north and east). 
areas of Grombalia, Nabeul and Soliman 6\% and 7\%. As for the other areas, this rate ranges from $0 \%$ to $3 \%$. Concerning the qualification rate, the industrial areas show noticeable differences varying from $42 \%$ in Kelibia to $8 \%$ in Korba, with $19 \%$ in Nabeul and 15\% in Soliman.

Knowing in advance that the exploitation of new technologies and the automatization (industrial sectors), as well as the increase in the number of enterprises (the industrial zones) where the guidance rates could influence the attitudes and representations hold heads of corporations about engineers and their hiring policy in the Cap Bon area, we took into account in our choice the number of employees per sector and category, as well as the guidance rates (those rates vary according to the sector and the industrial zone).

Industrial sectors: Mechanical and electrical, metallurgical and plastic industries, textile, ceramics, others.

Urban zones:

$1^{\text {st }}$ category: Grombalia and Soliman.

$2^{\text {nd }}$ category: Nabeul City.

$3^{\text {rd }}$ category: Kélibia, Beni-khalled, Menzel Bouzelfa, Bouargoub.

$4^{\text {th }}$ category: Dar Chaâbene, Korba, El Hawaria.

The 3/4 of heads of enterprises in the sample have been in this field for a period that ranges from 30 to 50 years. Their professional career has been marked by dynamism, full productivity and desire for innovation and improvement. Examining the data related to the academic level of the sample members leads us to conclude that it is an advanced one. In fact, $2 / 3$ of them have reached university levels; only $1 / 3$ has primary or secondary education levels. Our sample presents a positive academic experience that is likely to shape a positive attitude towards the graduates and, therefore, to be in favor of hiring engineers in their corporations.

The sample analysis in terms of the status of the interviewed head of the company reveals an imbalance in favor of the managers $55 \%$ compared to the proprietors $30 \%$. The highest proportion of managers can signify a change in vision and attitude since the proprietors or those who have the means to invest in the industrial sector resort to experts and to confirmed skills to manage enterprises. If we maintain the same logic, we assume that those managers would be in favor of hiring specialized high-quality senior technicians.

Out of the whole mass of the workforce in the sample enterprises, only $1 \%$ holds the status of engineer, which represents 88 engineers. If we add to this proportion of technicians and specialized workers, we reach only $16 \%$ of the total number of employees (187 technicians/ 748 specialized workers). The dominant category that rises to $83 \%$ of the total number is composed of simple workers. If we compare the weight of engineers within the total mass of senior technicians, we notice a proportion that doesn't exceed $7 \%$ while the weight of technicians rises to $20 \%$. The dominant category remains that of specialized workers, representing $73 \%$. The results confirm the already-revealed tendencies since the 
workforce is made up of $80 \%$ of workers; specialized ones don't exceed $12 \%$, technicians $4 \%$ and engineers $1 \%$. The proportions of senior technicians globally confirm the idea of the low hiring rates of specialized workers and graduates.

This means that we are faced with two opposed logics: the logic of training, which activates degrees and qualification levels (recognized skills), and the logic of production sectors which offers unqualified jobs. However, the change in the characteristics of enterprises must mechanically lead to a strong rise in the staff of engineers in the private sector. In fact, more than $45 \%$ of engineers are currently employed by state companies, and they represent by far the biggest contingency of Tunisian senior high technicians.

\subsection{Managers' Representations of Senior Engineers}

In the Anglo-Saxon model, enterprises are required to find the skills they need on the work market. The employability responsibility depends on the employee himself. It is in this context that the American universities publish "Employability skills Profiles" for the benefit of their professional training students. This associates technical skills with complementary capacities relevant to employability, as varied as the ability to communicate, solve problems and have a sense of decision, ethical values at work or an emotional intelligence.

For this reason, in his research Barkatoolah (2000) considers that skill management is not only a necessary for the employee, but also a decisive asset for the enterprises in the XXIst century. In the same context, we notice that the declaration of the European commission concerning lifelong training is in the heart of the European actualities. Focusing on education and training to involve European countries in the process of creating jobs and activities, while taking into account the globalization of the economy and the emergence of new technologies.

This is why degrees alone do not ensure work. Skills like knowing how to communicate, how to work with others, how to adapt, among others, are acquired before accessing a formal training system and evolving later.

Thus, we can say that the present skills result from the use of personal characteristics and a set of behaviours that clearly influence one's performance. In this approach, the intellectual skills are not enough to predict professional success; good performance is also the outcome of the qualities developed by the person in his current life through the experience he has undergone.

In fact, we can recognize the importance of one's self representation as a component of one's skills. The person's self-image is the result of what we have integrated in ourselves throughout our lives as well as what others have sent us regarding the roles played in our society: family, professional and social ones as they bring rules, norms and values. This means that skills are the result of the interaction between the social context and the construction of one's self-image.

According to this approach, professional skills and their mechanisms can't be understood unless they are linked to the social and affective history of individu- 
als and the culture of the enterprises. Since skills are nothing but a set of cognitive capacities, knowledge areas, values, attitudes, and behaviours that the person shows in a given situation and for an objective, which determines his commitment to the action.

In fact, the key skills allowing the creation of a component or part of a product contribute in a significant and essential way to the added value of the final product. Skills play a key role in the access to a potential global market. They are major sources of the competitive advantage that offers a superiority that is valued by the final customer.

Skills will obviously be technological and industrial, but they will also be organizational and managerial. Effective management is based on four pillars:

- The distribution of financial and human resources.

- The use of appropriate structures.

- The definition of information-spreading system.

- The development of a group culture.

In this context, and aiming to improve the performance of the industrial corporation, we will try to reveal the tendencies that firm managers envisage in the Cap Bon industry in order to improve production and performance.

Relying on the results of the research, we will notice a rising expectation of multi-skills, which represents a problem when it comes to employment, how can initial training bring about high skills in all fields? We are faced with a problem of general coordination between the training schools and the enterprises. In fact, each institution tends to define its own objectives and develop its own strategies without sticking to a global strategy framework that aims at developing senior technicians' training development in Tunisia. This characteristic partly explains the fact that $38 \%$ of interviewed industrial managers estimate that the training of engineers hardly responds to the needs of industrial enterprises, $36 \%$ find it satisfactory and $26 \%$ consider the experience far from being satisfactory.

Managers' attitudes and opinions seem to be divergent when it comes to appreciating or criticizing the training. We wonder why the interviewed firm managers tend to show a negative attitude towards engineers' training. Is it because the engineer's profile is based on theoretical knowledge and, therefore, disconnected from reality? Or is it because the profile of the training is too general and lacks a specific culture about the firm? Or is it because the engineer is out of touch with the policy of the enterprise and its objectives.

\subsubsection{Industrial Managers' Expectations from the Engineer}

When it comes to industrial manager expectations from engineers, a variety of answers were given. This proves that the engineer's contribution to the enterprise is overestimated, as if this senior expert had a master key to solve all kinds of problems. We have gathered the various answers and grouped them into six categories: problem solving, adaptation, guidance, initiative and prediction.

This leads us to the definition given by Beaudin of the four skills that the new engineer must acquire so as to be well-integrated: He must acquire trust inside 
the company; he has to behave in such a way that his authority, his knowledge and his experience will be respected (Durand et al., 2012). The aims and objectives of the engineer must be in harmony with those of the organization, in other words, the engineer's strategies and those of the management have to match with each other.

The newly-hired engineer is accepted at the interpersonal level, he is capable of creating good relationships with his colleagues. He has to provide the company with the high-level contribution that has been expected from him since he was hired. In order to reach the four dimensions, the engineer must begin by becoming aware of the following aspects: clarifying the role, creating links, learning the culture.

In this context, the new engineers had better begin by knowing the firm culture even before being hired. This can be done during the hiring process and the meetings. For this reason, we asked the interviewees where the real weaknesses of a new graduate lie. $32 \%$ of the sample heads of companies find that the young senior technicians are not capable of maintaining good communication with the employees. That is, they have, above all, a relational handicap, $27 \%$ insist on the poor training of engineers.

This means that even within the content of the job, the part left for adaptation, imagination and creativity may transform the job and facilitate highlighting motivation. This is the start of a new form of predictive management of the expected job, no longer at the company level, but at the level of the individual himself whose professional future can be planned. This is called employability, in other words, the worker's ability to meet the required and sufficient conditions to maintain and find a job inside or outside the company (Barkatoolah, 2000).

Employability consists in acquiring the capacity to ensure one's maintenance in a job, the capacity to move towards close or neighbouring jobs, the capacity to change a job, a company or a professional sector. Development and employability consists in extending the technical capabilities and skills to acquire a certain level of autonomy and responsibility. It means giving the worker, especially the senior technician, the individual skills, broadened and complementary, even if they remain close to the held job. The need to develop individual or social capacities allows the individuals to adapt to new technical, economic and cultural contexts. This is what we highlighted in the answers of the heads of enterprises and confirmed by (Pérez \& Canino, 2009) in their study dealing with the importance of the entrepreneur's perception of Success.

Except for problem-solving and polyvalence, the other categories are almost of equal importance $25 \%$, adaptation $24 \%$ and initiative $23 \%$, which requires a high level of demands from the part of the industrialists. If guidance is the most common function in the engineer's activities repertory, industrialists expect senior technicians to anticipate the needs of the enterprise and improve production conditions, product quality and performance. 
Starting from those quantitative data, we can notice that textile managers' tendency shows the importance of, and even the need for, human resources in order to improve the functioning of their enterprises. The main innovation is to adopt an approach allowing the move from the logic of a position, a worker, a machine and an activity, to a logic of polyvalence, consisting in segmenting the activities in the process on the one hand, and in diversifying the missions on the other, with workers being led to manipulate many machines. This reform has led to a modification of the internal organization of workshops and team work.

We have moved from position to mission, by gathering a group of operators mastering the required skills for the creation of a process or a process segment, and turning them into a team. Accordingly, the work of senior engineers and head of teams has evolved deeply, moving from a role of hierarchic, classical guidance to the status of an animator including the training mission.

In order to respond to the strategic action objectives, skill can be defined by Paradeise and Lichtenberger (2001) as the capacity to master a situation within one's professional activity, but equally as the capacity to evolve one's skills to face new situations. Skill is not linked to the function. It is also people's capacity to assume individually or collectively the company's evolution.

We define as social skills those that are required for an effective communication with others. In the work setting, those communicative qualities are revealed through the capacity to trigger synchronized behaviours that are oriented towards a common goal (Paradeise \& Lichtenberger, 2001).

In fact, today's society is at the same time based on knowledge and organizations, in mutual dependence. It functions on the basis of two cultures: the senior technician needs the organization as a tool that allows him to practice his skills, and his specialized knowledge. As for the head of the enterprise or the manager, he considers knowledge as a means to improve the efficiency of the organization.

The main problem of social relationships is the question of power. What we have to do is not how to learn or exert power, but rather how to develop it (Follet, 2002). For this reason, the successful firm manager today is the one who knows how to spread intelligence areas, while taking into account the main functions of the leader such as coordination, defining objectives, and anticipation.

In general, focusing on the obtained results, we can deduce that in the current management of the enterprise, the frequent need for varied and independent skills (adaptation, guidance, initiation and anticipation) reflects the need for an engineer manager and not an engineer who possesses only scientific skills. This is the perspective for a young engineer in the world of enterprise and work market.

\subsubsection{The Requirements for the Position of an Engineer}

Almost half the firm heads who answered the questionnaire insist on polyvalence in practicing an industrial job in all sectors. Polyvalence represents multi-skills, mastery of various jobs and sharp expertise. In this case, the individual's optic effec- 
tively leads to great employability. Multi-competence in terms of opportunity consists in widening the activities through an apprenticeship process in diverse working contexts.

Multi-competence in terms of rationalization, which has a purely economic objective, tends to reduce the cost of human resources. Polyvalence by mobility from an individual, a position (or function) to another is not possible unless the need in terms of skills, autonomy and responsibility is small.

The profile of the position is equally defined by the requirements that seem opposed, the group spirit 35\% and the autonomy 13\%. Thus, the senior engineer in industry can reconcile what is related to individuality with what is related to the team. Consequently, he is obliged to look for certain homogeneity in his team by sharing values and common goals, and a certain homogeneity of personalities as an enriching source of creativity. In addition, our education, founded on individualism and our training sessions and promotions based on competitions and individual worth, are not in favor of a spontaneous emergence of a group spirit. This individualized management started with school studies that are rather competitive in order to access the hoped engineering school.

It would be an illusion to think that those people were spontaneously oriented to group work. Autonomy in industry as a constituent dimension in the profiles of professional positions obtains only very low proportions in the answers of industrial sectors managers. This could be due to the reticence of those managers when it comes to senior technicians exercising their functions. This low proportion confirms the explanatory hypothesis related to the engineer's autonomy, whatever his field of work is.

It is as if there was a widespread culture among the industrial managers, especially when they face situations of conflicts. The amount of this data can't be explained simply by the dysfunctioning of the education system and the lack of adaptation of the university training to the needs of the enterprises. The employment crisis of young senior technicians is mainly linked to the insufficiency of job creations.

Employment stability, career, responsibility, insurance of university degree, those distinctive traits of the senior technicians of the years (1950-1970) are, thus, threatened by the seriousness of the employment crisis and also by the socio-technical mutations that lead to a certain decomposition of the operatory functions. In this context, what role can the engineer play in the Cap Bon industrial enterprise?

We are witnessing, nowadays, the difficult creation of a global production space that integrates three great function categories:

The functions of productions of production system conception and renewal.

The functions of highlighting those functioning systems.

The function of pioneering and regulation of the conception as well as their execution, which manage under constraints the objectives of those systems.

The creation of this global production space signifies that there were some activities and temporalities that remain qualitatively distinct, and that were con- 
ducted and oriented as if they were nothing but particular moments of the same phenomenon "the industrial production in the strong meaning of the word (Michou \& Segrestin, 1990). This could be translated by the role of the employment market as a mediator of relations between the world of industry and that of training and research.

For a few years, the heart of organizations has been beating at the speed of globalization and the new economy of knowledge. How to qualify senior technicians who are required to be visionary, creative and "go-ahead type"? Previously, a senior technician could be the producer of the changes in the organization of his enterprise, but since the years 1980, some phenomena that are by far beyond his reach have appeared and relativized his influence and freedom of action. Restructuration, organizational flexibility, firm internationalization, refocusing, this process blurs the strategy of the enterprise that is becoming more and more at the service of shareholders.

The existence of institutionalized barriers was notably by the access degrees. The areas of knowledge are split into bits and do not lend themselves to a unique formal training. Finally, its functioning mode remains, before all, the project, which tends to lock it in a more restrained universe than the enterprise or the profession. The new profile is that of someone who develops a new habit, that of learning permanently, he possesses, in this way, his main production tool, his knowledge: an industrial engineer also rhymes with manager. Taking into account the financial, organizational and human aspects of the project is also part of his mission without forgetting communication, organization, planning and team management.

In order to master the various tasks, polyvalence seems to be the key word in this job. The ideal profile is, thus, that which allows him to intervene with the equipment no matter what the technology involved is business leader in electro-mechanics. The safety exploitation engineer intervenes with the set of production units to help the exploiter solve the technical problems related to safety. The radioprotection engineer takes charge, with his teams, of the radiological protection of individuals and property. The laboratory engineer is responsible for all the analytical techniques applied in the laboratory. He ensures the execution of analysis procedures, especially the insurance-quality procedures.

From the results obtained from our present empirical enquiry, $18 \%$ of interviewed heads of enterprises expressed their needs in management engineering. This reflects their concern about ensuring good management of the different resources in order to optimize and ensure better production. The contract manager ensures the interface between the factory and the customer. He ensures the good execution of the contract, the respect of commitments and the planning of the operations. Finance jobs are equally very frequent in cycle factories: accountant, management supervisor or head of economic studies. Finally, cycle factories have senior technicians in human resources jobs (staff manager, head of 
staff management department, head of the employment and training department, social relations manager) in communication jobs or in the legal field.

\section{4. "Knowledge Professionalization" Culture}

From the answers of Tunisian industrial managers in the Cap Bon areas, the latter need managers who have taken a role that is becoming more and more important with the execution of participatory management based on interdisciplinary skills. In order to reconcile efficiency with respect for the individual, and allow each person to use his capacity to take the initiative and prove his aptitude to react to the modifications of the situation, we notice that enterprises have never communicated their values and culture. We may see a cause-effect link here.

Because of the market requirements that are getting more and more varied and complex, as well as those of the direct and indirect environment, the thought about the enterprise has evolved, moving from a linear form into a more complex, global and globalizing one. How can we master and maintain a pertinent and intelligent information system while evolving?

We have to solve practically the integration of the determination of human objectives as well as the effective and satisfactory means in a multiple dimension, a totally cultural dimension. That is the key to any responsibility; understanding, orienting, acting, those are the three registers where the art of entrepreneurship is achieved.

Faced with the complexity of the market, of the means of communication, and the management of internal and external data of the enterprise, any action has to be closely linked to a precise and justified sense before it is deeply mastered. Culture is certainly not mentioned, but it will not remain implicit.

Culture seems to serve not the reflection, but the mediation between the subjects, whether he is inside or outside the company, and his environment. There are two structuring aspects of a definition culture which are the descriptible specific content and the mode of description of the organization, a reading grid of the human society (Thévenet, 1993). This comprises the importance of the culture content which influences behaviour direction and its strong influence on behaviour intensity (Sathe, 1985). However, it equally suggests the need for an adequacy between individual values and the purposes of the organization.

This economic, social and heterogeneous community needs a relatively harmonious coherence in order to function in an optimal way. Any enterprise, whatever size it has, makes a social subgroup composed of individuals seemingly belonging to one or many national, regional or professional cultures. In order to ensure the coherence of this mosaic, the enterprise needs to create a collective identity that will serve as a reference for all its members.

The enterprise culture can be defined as a set of particular elements that explain the functioning bases of a specific entity. It is to a certain extent, a sub product of the national culture and, therefore, a set of values, myths, rituals, ta- 
boos and signs shared by the majority of workers. Godelier (2006) words the enterprise as a coherent whole in which culture constitutes at the same time the sink of transformation and the ultimate objective of restructuration.

The enterprise culture transmits values that serve to spread energies and orient the employees' behaviours so as to achieve the goals of the enterprise. Thus, the enterprise culture is a useful element to develop the employees' involvement in the enterprise in order to improve its performances.

We wonder in what way the enterprise culture can constitute a tool of motivation, a place for socialization and, therefore, an institutional frame for identity construction. Knowing that modernization is widely founded on the precarity of employment and the need for the flexibility of enterprises towards their employees, what are the real concerns of corporation managers in this context?

In fact, the enterprise culture is believed to be essential for explaining everyday happenings and the strategic choices of industrial corporation managers in the Cap Bon area. Concerning industrial managers' concerns, the criteria and the means of promoting senior engineers and, eventually, the integration methods of young engineers into the new professional life.

By raising the issue of improving the performance of the industrial enterprise, we will try to reveal the tendencies anticipated by the industrial actors in the Cap-Bon so as to improve production and performance. We were able to discover that $47 \%$ of industrial managers pay great attention to the evolution of human resources training for the productivity of their industrial enterprises in all the economic sectors against 39\% for the development of technological and instruments and equipment, while moral and material recognition doesn't exceed $9 \%$. This gives us a clear idea about the work conditions in the industrial enterprises in that region.

The principal innovation was to set a device that allows the move from the logic of a position, a machine and an activity to the logic of polyvalence. This reform has led to a modification of the internal organization of workshops and work teams. We have moved from position to mission while gathering into a team several operators that master the skill required for a process or a segment of it.

Correlatively, the job of senior engineers or team leaders has deeply evolved, moving from the classical role of hierarchic guidance to a status of an animator including the mission of training. In order to respond to the strategic objectives of the action, skills are defined as the capacity to master a situation within one's professional activity, but equally as the capacity to help evolve one's competences so as to face new situations (Schein, 1985).

While searching for those skills, we have tried to reveal the hiring strategies adopted by enterprise managers in the areas. We continue to hire essentially according to the criteria of diplomas and cultural style, more than half $69 \%$ of young engineers are hired via competitions and training sessions. The example of hiring young senior technicians is particularly significant when a set of para- 
doxes are updated, like the fact that it is hard for the enterprise to match speech with reality. The enterprise, especially the big one, demands new men, new profiles, it is the personality that it looks for, not the diplomas.

It seeks dynamic candidates who have the desire for taking the challenge, knowing how to adapt to all situations and who are capable of communicating easily. However, in reality, we continue to hire the same candidates as we used to fifteen or twenty years ago, they are chosen in the same great engineering and management schools, without wondering if the received training corresponds with the desired criteria.

According the interviews conducted with sample industrial managers, three qualities arise: the work technique dimension (experience) 37\%, the social dimension $13 \%$ that is the ability to integrate in a work team, the relational and behavioural dimension like involvement $19 \%$, the sense of responsibility, the management of priorities while dealing with constraints and encountered problems.

Thus, the notion of experience includes the fact of experiencing (or living), as well as the situation (or the event) experienced or lived, or also the knowledge acquired through this means. The situation is referred to as the singularity, as opposed to the generality or the banality. Knowledge is referred to as a capitalization of what was learnt from the situation. In fact, having experience means having lived situations, in the case of the professional experience, but it, above all, knows how to learn the lessons.

The treatment of the answers to the question of selection criteria in industrial zones shows that professional experience is required in all the zones by an enterprise manager out of two or by two out of three. In general, and from the obtained answers, experience can be a source of knowledge only if it respects certain existence conditions (sometimes close to the scientific experimentation) and is treated according to a rational process. The areas of knowledge derived from the experience are often the object of hierarchisation:

Empirical knowledge: it is the outcome of traditions, personal life experience and also, for some people, professional experience.

Rational knowledge: it is based on laws and not beliefs or know-how. It is more certain, precise, general and systematized. It can also be blamed for being dogmatic.

Scientific knowledge: it is based on rational knowledge and its engines are doubt, "the scientific spirit" and the search for evidence.

The professional experience constitutes a warning for hiring managers and a means to benefit from the service of newly-hired employees as soon as possible and with as much efficiency and productivity as possible. Demanding professional experience would have several effects on young candidates and enterprises since the hiring process will be limited and delayed.

The professional experience seems to have an equally powerful and symbolic role, the valence, which is variable, according to professional setting. We are 
dealing with the visible professional experience, marked by physical characteristics, by an age. If this professional experience can't alone determine the validity and legitimacy of an action, it determines the credibility of the actor, his legitimacy to act, and his skills in action.

The global results show a great worry from the part of heads of enterprises about the technical aspects as if the good functioning of the enterprise depends solely on the optimal conditions of the equipment and production modes. This reflects a Taylorian conception of the work organization reinforced by the importance given to the supervision of production rhythms and quality as well as the optimization of resources and potentials. On the other hand, $10 \%$ of the answers mention the psychological aspects related to the motivation of the workforce (senior technicians, workers, and employees), the renewal of its energies and the modes of rewarding and encouragement.

At the economic level, the enterprise culture can help improve performance. Adherence to the values of the enterprise and the development of motivation allow better coordination, facilitate synergies, and ensure a better integration of new employees. However, we have to be imaginative by offering enforcements other than the financial ones, for example, by exposing an employee with intellectual challenges, assigning him more duties, granting him more autonomy, and, why not give him more freedom of action when it comes to decision-making.

Most of the enterprises in the Cap Bon area include, in their rewarding plan, a system of perks that offers the possibility of working harder in order to gain more. In this context, we consider that money, like all the working conditions, is a satisfaction factor. This motivates some individuals, but not everybody.

It is not simply money, but rather the tangible recognition of success, the enriching of tasks that offers senior engineers real satisfaction with their work, the modified power delegation, and this process is called participatory management, responsibility, mobilization and participation. Those are the most commonly used words nowadays; we will rather talk about involvement and cognitive dynamism. The competence model promoted today by the MEDEF is closely linked to a more global strategy: redefining employment and the work organization, which ignores Taylorism and its rigidities, is based on flexibility and highlights mobilizing employees' commitment against the search for their conformity, their initiative capacities and their autonomy against their subordination, confidence against control, the learning enterprise against the frozen organization.

It is this professionlization process that we demand for the engineer student, a theoretical phase organized by the universities, paving the way for the practical professional phase. This competence logic aims at professionalization objective. The culture of "knowledge professionalization" has been one of the major challenges of engineers' university training in the last years and, pedagogic strategy to the employability of their graduates, we have to encourage the correlations between the university training offer and the needs/expectations of the economic world in terms of professional qualification and competence by developing 
partnerships with enterprises. Those senior managers work on what is called "the ethic" of enterprises, the norms and values super impose when it comes to the economic, technical and political forces.

According to the opinions and attitudes voiced concerning the engineer and his real and expected skills, whatever his sector or field of work, there is a widespread culture among industrial enterprise managers, especially when they are faced with situations of conflicts. From the previous statistical results, we notice that, from the start of the 1990 decade, it is mainly the young graduate engineers who are faced with the work market.

However, the change in the enterprise proprietorship must mechanically lead to a sharp rise in the number of engineers in the private sector. In fact, more than $45 \%$ of engineers are currently employed by state firms, and they make up by far the biggest contingency of Tunisian senior technicians. Do the insertion difficulties faced by young engineers on the work market in Tunisia, compared to their elders prove that they are professionally unqualified?

In order to grasp the strategies needed to develop industrial enterprises and improve their production and performance, the heads of enterprises insist on having senior engineers, who are capable of reading and interpreting the situations with objectivity, able to effectively respond without any emotional involvement, to manage other people's emotions and remain neutral, to anticipate, recognize and satisfy customers' needs.

In this case, the engineer's competence is no longer linked to the function. It is also up to people's capacity to assume the enterprise's evolutions both individually and collectively. It is the social skills that are necessary for an effective communication with the others. However, we can mention that the enterprise seeks to ensure its competitiveness not only in the short term, but also the middle and long term, relying on its main asset, namely the sum of competences it has in the first place and the technical level in the second place. This shows a need for guidance, which has a critical and ambiguous role, a technical and social role.

What we could notice from this study is the importance of the enterprise manager or the first man in charge of the Cap Bon industry in decision making concerning the evaluation of skills, which confirms the existence of an organization that is rather frozen by conservatism and inertia, since the power of taking decisions is most of the time in the hands of a set of managers rather than individual leaders. Paradoxically, this ethic generates a bureaucratic culture for the enterprise, whose managerial culture prioritizes rationality and control, the energy focuses on the objectives, resources and structures of the organization. Those individual skills represent an integration and a coordination of know-how, areas of knowledge and individual qualities in more effective organizational strategies that can rely on a strong cohesion between three key aspects: the individual skills, the technical knowledge of the organization and the managerial culture.

In fact, we can deduce that the autonomy and the organization of the indus- 
trial enterprise in Tunisia are in a state of opposition since autonomy is seen as the person's capacity to determine freely the rules of action to which he is submitted to set, within his space of action, the precise modes of his activity, without any norms imposed by the formal organization. The autonomy is a delegation that is sometimes total (but under conditions) of the decision-taking power to be applied later without any supervision or classical control.

The subordinate will be assessed in terms of results and the extent to which the objectives have been achieved. He will, therefore, be free to choose the implementation mode of his mission or the activity for which he is responsible. This goes in harmony with the hypotheses developed by Crozier and Friedberg (1977) on the power that could detain each social actor in terms of the size of his uncertainty zone and his expertise level. Each side (senior managers-senior engineers) would seek to broader, as much as possible, his freedom of action in order to have more power of negotiation with his rival and try to benefit more than his colleagues.

If we follow this logic, the enterprise managers won't appreciate seeing their power dwindle by granting more autonomy to their senior engineers, they will struggle to preserve it. Thus, there is a game between the managers and the senior engineers in order to master the uncertainty zones. By granting his subordinate a higher degree of autonomy, the manager will lose part of his power and, therefore, he will lose his power, often the manner (the mode, the process) in which the required job will be done.

Tunisian engineering schools generally tend to train conception engineers. Within the training course, little is devoted to training practitioner and polyvalent engineers as long as the dominant focus is to prioritize the principle of apprenticeship through practice, during the professional insertion period. Nowadays, the job of an engineer has become particularly complex because of the diversity of technologies and activity fields. The polyvalence of the engineer's profile is becoming a growing necessity voiced by employers.

From the Cap Bon industrial proprietors' answer, it is clear that they need managers who have taken an increasingly important role with the implementation of participatory management based on interdisciplinary skills. In order to reconcile efficiency with the respect for the individual, in order to allow each person to use his initiative capacity and prove his ability to react to the modifications of the situation, we notice that the enterprises have never explicitly expressed their values and culture.

In this context, management focuses particularly on culture when it comes to managing men and especially senior technicians with a scientific potential at a high level. Economists estimate that the enterprise can motivate the individual by allowing him to identify himself with it by means of the enterprise culture. It is for this reason that prior knowledge of the enterprise culture is necessary for every strategic reflexion. It allows taking an adapted decision, while taking into account the specific features of the enterprise, avoiding to fond on those decision compared to the standard norms. 
In order to aim at the transition from a community that has become closed to a society that is more open to its real internal forces, and to its multiple environments, the enterprise needs to develop its new social identities and recognize the collective logics. In order to make the development an expression of the social system, the combination of personal evolution projects in terms of the private life path with the collective-constructive projects must become a strategic commitment.

This policy has become one of the major challenges for the change-maker in the enterprise. The participatory actions have produced some cultural effects in the life of the enterprises, which brings about the idea that an act of change will not succeed nowadays unless we focus on the involvement of managers and employees through the common achievement of future projects. "The deep change of a social system can't be achieved without particular structure, with the objective of setting in motion a social around a team of actors united by intervention, conduct, and evaluation of changes of social relationships justifying a change in the policy (Paradeise \& Lichtenberger, 2001).

On the other hand, today, the major impact of the Internet is questioning the techniques of commercialization and distribution of new services (banks, stock market). In order to face the challenge of the globalization of the economy, enterprises need:

- a capacity to deeply redefine strategic alliances.

- to precisely follow what others do at the technical level and know what is happening in the market.

- to set new projects as fast as possible.

Those new requirements make it necessary to define the new profiles of engineers: strategic engineers, open to international settings, with a good knowledge of the economic reality, and able to be involved in the financial happenings like engineers with technological concerns, application engineers (follow-up of customers), engineers in the commercial system and engineers in conducting projects. In front of those professional obligations, a motivational and integrative culture can't be introduced into our industrial enterprises without a new organizational strategy, which calls for flexibility as a capacity to adapt to a continuously changing market. In certain enterprises, there is no longer a defined position, as the focus is put on the employees.

For other enterprises, functional flexibility helps to redefine tasks. In their search for functional flexibility, enterprises call for the autonomy and the initiative of senior engineers. This type of flexibility develops the staff's polyvalence as well as the mutual help between the different jobs within the enterprise.

The practices of human resources management have become more individualized in order to take into consideration the specific traits of each job. This strategy of management comes from the diversity of forms of work within the same organization. So we have to adopt distinct practices aiming at motivating or mobilizing workers depending on whether the employee is permanent or one who has a work contract for a determined period. Managers very often resort to 
outsourcing, reducing the amount of their workforce. They have equally modified the conditions or the nature of employing a lot of workers.

Thus, many workers have moved from a steady full-time job to a part-time one or have become autonomous workers. Those decisions have resulted in increasing the presence of atypical workers on the work market, especially after the revolution (2011). By looking for peak flexibility, resorting to atypical workers is explained by greater flexibility in functioning and greater capacity of enterprise adaptation to the market needs and fluctuations.

They can adjust the size of their workforce according to the production needs. The part-time contracts, those on flat rate, and especially those obtained via a placement agency are economic sources as they lead to lower pay and exemption from paying social advantages as well as the absence of an unproductive period (Le Louarn, 1990). The objective of flexibility can also be translated by the expectations of enterprises in terms of the employees' qualifications and polyvalence, in such a way that the positions and the management policies of human resources witness important modifications. This career management belongs to the new competence mode which is opposed to the modes of status, jobs and qualifications (Mercure, 2001).

In this new context marked by various uncertainties, by the complexity and globalization of phenomena, it is essential to wonder in what way globalization and the establishment of the free-exchange zone will affect the highlighted strategies and what strategies the enterprise must adopt in the Cap Bon area. The need for flexibility is linked to a redefinition of performance, inter-enterprises relations, communication, and decision processes inside the firm. In this context, the upgrading of the industrial enterprise requires taking action about the staff, the functions, the tasks, the organization and the strategies.

\section{Conclusion}

Training engineers in Tunisia has reached a maturity stage at the quantity and quality levels. The interviewed industrial proprietors in this opinion poll, belonging to different sectors, affirm that the set of training devices for engineers continues to train them while getting inspired by classical approaches founded on frozen training courses, leaving very little freedom of action for trainers to introduce actions of change and innovation.

The obtained results of our enquiry indicate that the lack of some engineering fields in Tunis universities represents an obstacle that cripples starting and improving an active partnership between the two partners: the university and the enterprise, especially for the electro-mechanical sector, textile and, at a lower rate, for farming and ceramics. This shows, at first sight, the inadequacy between the training system and the employment needs of the market in terms of engineering.

Similarly, we notice that farming and textile show their dissatisfaction with the present training system for engineers at university and suggest the need to 
adopt a kind of training that alternates industrial proprietors with university experts at a lower rate since the contacts with the professional setting are not well-developed to the point that the participation of the private sector in the orientation and the recast of training courses has never been on today's agenda.

We can suppose that the particularity of our industrial enterprises is based on a fragmented and partial production and is characterized by the implementation of pre-established devices and courses, they don't show a great need to conduct researches that can lead to new systems and new manufacturing procedures.

Thus, training new senior engineers and integrating them in the active life remain burning issues in the employment policy in Tunisia. Aware of the stake, all the economic and scientific actors are committed to creating partnerships in order to prioritize hiring qualified and competent workforce. It is in this context that a solid partnership with the higher education engineering institutes and industrial enterprises in the different sectors will have great importance in the contribution to the qualifying training of teachers, to the improvement of young graduates' employability and to the reinforcement of those future engineers.

This type of training philanthropy is an excellent opportunity for our youths in order to have easier access to the active life, besides the mastery of the skills acquired by the student after the training, they develop in terms of conception methodology, and applied industrial and mechanical production, leading to graduates who are more qualified and better adapted since the needs of the industry have been taken into consideration. Whatever the country in which the university-enterprise partnership happens, this reciprocal action requires initiatives and encouragements.

It can't always be produced spontaneously. However, it mustn't be imitated; it has to be born from an awareness of interdependence, and recognition of mutual needs. The enterprise and the university have to be certain that this collaboration will be mutually rewarding and it will take a lot of time and efforts to convince them to collaborate.

We can deduce that hiring plays the role of an integrator besides its function as a selector. Starting from this representation of senior managers, we could find out how they see the role of the engineer or, precisely that of guidance.

Finally, industrial enterprise proprietors have a representation of the role of an engineer based on the notion of systematized guidance. However, senior technicians are not totally a category that is similar to workers, in whom employers have less confidence. This trust lies in a particular field, that of the person who has a managerial power over subordinate workers, a power whose guidance is the delegate as much as the interpreter of confidence, giving the first sign of representation of both the organizational position of the senior manager who doesn't tend to delegate his power to senior engineers who are not recognized much autonomy. Since enterprise managers consider that the general function of guidance consists in translating into technical solutions all the economic and financial intentions of the enterprise managers. 
The psycho-sociological analysis of the representation of the enterprise manager about the issue of senior engineers' hiring has contributed to highlighting the risks related to applying changes, to showing the real functioning of the organization compared to the instructions, and, thus, to the incoherence between the managerial objectives that are pursued and the way the decisions were taken, the ultimate consequences of this incoherence could consist in ending the process of hiring new engineers. We can refer to this as the impact of the social on the employment issue.

Finally, it seems that the representation that the manager has about the senior engineer has to do only with the uncertainty about the social, while the rationality of the manager involves other elements that are far less appreciable for us, like the technical, organizational and economic uncertainties linked to changes.

In fact, the rebounds of this analysis have helped us to discover the dimensions that were not immediately perceptible or comprehensible in the position of the manager actor towards the engineer and especially the low rate of guidance in industrial enterprises. We know that a strategic interest is also taken into consideration. But it is equally the ethic of the manager that is revealed in this situation. The deep interviews with the senior managers have helped us understand the global meaning they have of his mission in a context that is far from being neutral: that of hiring according to objective and rational criteria, motivating the engineer or guiding him, and especially, the way of evaluating his skills and knowing his performances.

They are the manager's representations of political and ethical types, which we discover partly, as well as the reasons for his commitment to the act of senior technicians' hiring. We can't help thinking that it is also an ethical register that has vibrated in the manager's mind when he warned many times about the risks of the inadequacy between the university training based on a qualification strategy and the real needs for industrial managers founded on a competence-based strategy.

\section{Conflicts of Interest}

The authors declare no conflicts of interest regarding the publication of this paper.

\section{References}

Barkatoolah, A. (2000). Valider les acquis et les compétences en entreprise. Paris: INEPS.

Ben Salem, L. (1994). Les ingénieurs tunisiens aux XIXe et XXe siècles. Revue du Monde musulman et de la Méditerranée, No. 72.

Bonardi, C., \& Roussiau, N. (2001). Les représentations sociales, Etats des lieux et perspectives, Mardaga.

Covin, J. G., \& Wales, W. J. (2012). The Measurement of Entrepreneurial Orientation. Entrepreneurship: Theory \& Practice, 36, 677-702. https://doi.org/10.1111/j.1540-6520.2010.00432.x

Crozier, M., \& Friedberg, E. (1977). L’Acteur et le système, Les contraintes de l'action 
collective. Paris: Éditions du Seuil, Collection Points/Essais.

Doise, W. (1973). Relations et représentations entre groupes. In S. Moscovici (Ed.), Introduction à la psychologie sociale (Vol. 1). Paris: Larousse.

Durand, C., Fili, J.-F., \& Hénault, A. (2012). Culture d'entreprise. http://culture.entreprise.free.fr/\#_Toc476995189

Follet, M. (2002). Diriger au-delà du conflit. Paris: Village Mondial.

Godelier, E. (2006). La culture d'entreprise. Collection Repères, Paris: La Découverte.

Jodelet, D. (1984). Représentations sociales: Phénomènes, concepts et théories. In S. Moscovici (Ed.), Psychologie sociale (pp. 357-378). Paris: PUF.

Jodelet, D. (1985). Civils et bredins rapport à la folie et représentation sociale de la maladie mentale. Thèse pour le doctorat d'état, Paris: EHESS.

Jodelet, D. (1989). Les représentations sociales. Paris: PUF.

Kelly, H.-H., \& Michela, J.-L. (1980). Attribution Theory and Research. Annual Review of Psychology, 31, 457-501. https://doi.org/10.1146/annurev.ps.31.020180.002325

Kvale, S. (1996). Interviews: An Introduction to Qualitative Interviewing. Thousand Oaks, CA: Sage Publications.

Le Louarn, J.-Y. (1990). Les emplois atypiques et l'efficacité de la gestion des ressources humaines, dans, Le défi de la gestion des emplois, sous la direction de Jean Boivin et autres. Québec: Les Presses de l’Université Laval.

Lotz, H. M., \& Van Der Merwe, S. P. (2013). An Investigation of the Influence of Entrepreneurial Orientation on the Perceived Success of Agribusinesses in South Africa. Journal of Business Management, 44, 15-32. https://doi.org/10.4102/sajbm.v44i1.145

Mercure, D. (2001). Nouvelles dynamiques d'entreprise et transformation des formes d'emploi: Du fordisme à l'impartition flexible. dans L'incessante évolution des formes d'emploi et la redoutable stagnation des lois du travail, LV le congrès des relations industrielles de l'Université Laval, Les Presses de l'Université Laval, Sainte-Foy.

Michou, F., \& Segrestin, D. (1990). L'emploi, l'entreprise et la société. Paris: Economica.

Miller, D. (1983). The Correlates of Entrepreneurship in Three Types of Firms. Management Science, 29, 770-791. https://doi.org/10.1287/mnsc.29.7.770

Moscovici, S. (1961). La psychanalyse, son image et son public. Paris: PUF.

Ordre des Ingénieurs Tunisiens, OIT (2015). https://www.espacemanager.com/conseil-national-de-lordre-des-ingenieurs-tunisiens. $\underline{\mathrm{html}}$

Paradeise, C., \& Lichtenberger, Y. (2001). Compétence, compétences. Sociologie du travail, No. 43.

Patton, M.-Q. (2001). Qualitative Research \& Evaluation Methods. New York, NY: Sage Publications.

Pérez, E. H., \& Canino, R. M. B. (2009). The Importance of the Entrepreneur's Perception of "Success". Review of International Comparative Management, 10, 990-1010.

Rapport final du GEFI (2015). Une nouvelle vision du Système National de Formations d'Ingénieurs. http://www.mes.tn/image.php?id=5022

Resmi, A. T., \& Kamalanabhan, T. J. (2010). A Hierarchical Regression Analysis to Understand the Antecedents of Entrepreneurial Success. International Journal of Electronic Customer Relationship Management, 4, 377-394.

https://doi.org/10.1504/IJECRM.2010.036185 
Rubin, H. J., \& Rubin, I. S. (2005). Qualitative Interviewing: The Art of Hearing Data. New York, NY: Sage Publications.

Sathe, V. (1985). Culture and Related Corporate Realities. Homewood, IL: Richard D. Irwin.

Schein, E. H. (1985). Organizationel Culture and Leadership. Jossey-Bass.

Tajfel, H. (1972). La catégorisation sociale, In S. Moscovici (Ed.), Introduction à la psychologie sociale (Vol. 1). Paris: Larousse.

Thévenet, M. (1993). Impliquer les personnes dans l'entreprise. Paris: Editions Liaisons.

Turner III, D. W. (2010). Qualitative Interview Design: A Practical Guide for Novice Investigaors. The Qualitative Report, 15, 754-760.

Welman, Kruger, \& Mitchell (2007). Research Methodology (3rd ed.). Cape Town: Oxford University Press. 